\section{Cockcroft: a novel perspective}

\section{William Cooper}

Cockcroft and the Atom.

By Guy Hartcup and T.E. Allibone.

Adam Hilger, Bristol/Heyden, Phila-

delphia: 1984. Pp.320. £18.95, \$34.

SINCE the title of Hartcup and Allibone's book may sound a bit vague, perhaps I should begin by saying what Cockcroft and the Atom is about. It does not set up - as it seems to me - to be a full-dress biography of John Cockcroft (1897-1967), or a history of atomic science during the first half of the twentieth century; rather to be planned as a sort of documentary about the context of events in which Cockcroft's life, as scientist and man of affairs, was central, of events in the world of atomic physics that he influenced or that influenced him.

Does the plan succeed? For most readers 1 imagine the answer will be a straight "yes": for myself, some mild reservations. The book has been extensively "researched", as it is now called - records have been consulted, letters read, people interviewed; the facts laid end-to-end in chronological order. "A comprehensive compilation" is the phrase that springs to mind. (The mother-and-father of the comprehensive compilation is of course the computer.) Every event is noted, every participant named. Speaking as a novelist - and why not, if there is a fresh view to be added thereby? - I find something Zolaesque about the authors' naturalistic piling on of detail, maintaining throughout exactly the same degree of detail: what I miss is Zola-esque art; that is to say, in down-to-earth terms, an author's personal voice sounding through, an author's personal intelligence commenting and interpreting, an author's personal literary talent - the things that make one want to read a book for itself, as well as for the information it contains.

I don't doubt that many readers will feel I'm asking too much: out of 100 ears on which my mild strictures fall, 98 will probably be deaf to them. Just as well, perhaps, since the comprehensive compilation is with us, and will be so to an increasing extent. (Yesterday a youthful American pupil of mine said to me enthusiastically: "The word-processor makes writing so easy!' Just so.) However - to be fair - one can't help but feel that all the facts are there. Yet on some pages there are as many as a dozen names, normally far too many for comfortable reading. Comfortable enough for me in this case, because often half of them were of men I'd come across myself in my time; but for the comfort of other readers I'm not so sure. All the same, when it's compiled as successfully as this one, the comprehensive compilation undeniably earns its place in the library.

I was an admirer of Cockcroft, a fine, stocky, sensible, cautious Yorkshireman, who indulged in a minimum of speech and in practically no change of facial expression. (That expression was nevertheless amiable, thoughtful, smiling.) If one addressed a remark to him, it was only when, after the ensuing silence, he either took the famous black notebook out of his pocket or actually said something, that one knew for certain that he'd heard. It gave me lasting pleasure to think that at a dinnerparty in his house I'd made him burst into laughter - till I saw in this book a photograph of him laughing with George

The Cockcroft-Walton accelerator, April 1932, with Ernest Walton seated to observe the scintillations.

Gamow. Well, Gamow was a funny man. It was a theoretical memorandum of Gamow's which sowed the seed of the Cockcroft-Walton "atom-splitting" experiment, the first of its kind, in 1932. Cockcroft cottoned on to what Gamow was saying about bombarding elements with protons, and he addressed to Rutherford a calculation (reproduced in this book) that led to the famous experiment being set up. Then something odd happened. Using a lithium target bombarded with a beam of protons, Cockcroft and Walton began by looking for gamma-rays; and it was when Rutherford, fed up with their getting no results for a couple of years from their electroscopes, told them to install fluorescent screens, that they promptly picked up the alpha-particles into which the lithium atoms had been split; a prime experiment, for which the two of them were awarded a Nobel prize for physics - nineteen years later. James Chadwick, for discovering the neutron at about the same time got his Nobel in three years - very properly, for he had made what was in the sheer physics of it an absolutely fundamental discovery. The authors of this book take in their stride Cockcroft and Walton's being made to wait so long theirs not to reason why, they say. But what about ours? Did it take the Nobel committee nineteen years to recognize the experiment as breaking open an entirely new line of powerful experiments to be made with particle-accelerators? Or did it take those members who opposed the award all that time to disappear from the scene? Or what? Someone must know. There's a fascinating detail I should really like to be told.

Chadwick, speaking clearly for the "physics-is-physics" school, said of Cockcroft:

For example, his knowledge is wide but it is not at all profound; his views are of rather a dull everyday hue. On the other hand his temper is so equable and his patience and persistence so inexhaustible that we can put in lively and relatively irresponsible men who have the real feeling for research without fear of upsetting the balance.

I sense a pleasing Jane Austen-ish snobbery about the physics-is-physics school to which Cockcroft was neither born nor bred. He was an applied physicist. Between leaving school and turning up at Cambridge in 1922 to read for the Mathematical Tripos, he had taken a mathematics degree at Manchester University, served as a signaller in the trenches at Passchendaele, returned to Manchester Tech to take a degree in electrical engineering while doing a Metro-Vick apprenticeship. Yet how right Chadwick's intimations turned out to be, of what Cockcroft could be entrusted with, both inside and outside the world of physics - spending the early years of the Second World War on the vital practicalities of radar; then taking over the wartime atomic scientists' team in Montreal and Chalk River; then coming back to run them in Harwell, each team having its contingent of "lively men with a real feeling for research". (As I was party to appointing many of the Harwell contingent, I should be the last person to say any of them were "relatively irresponsible".)

"Without upsetting balance." That exactly describes Cockcroft's reign at Harwell from 1946 to 1958 , during which he directed some of its most important research: he may have been neither a super administrator nor a born manager - but the place balanced.

The authors observe that Cockcroft had his failures and disappointments, made his mistakes. He made a mistake - astonishingly against caution - with his overoptimism about the experiments aimed at generating power from fusion. And his private hopes of going back to his old college, St John's, Cambridge, were dashed when, in a magisterial election which reminded him and his wife of C.P. Snow's The Masters, the Fellows elected 
the Senior Tutor, and not Cockcroft, to be their Master. The upshot was a turn in his career, a definitive turn to Whitehall and national affairs. It is interesting to speculate whether, if he had gone back to Cambridge then, he would have played a comparable part in first national and later international affairs (though in a less definitive way he was already embarked on both.) $\mathrm{He}$ was persuaded to join the Defence Research Policy Committee. As a committee-member in the conventional sense, he was practically a non-starter, for the simple reason that he rarely said anything; but that didn't mean he was not cogitating, participating and resolving on action. His action took place outside the committee-room, in private meetings with the members and other people one at a time. "I flit from office to office", he wrote in amusingly candid self-observation - and with a spark of literary talent.

In his days at the Cavendish Laboratory in Cambridge, Cockcroft's colleagues had remarked on his extraordinary gift for switching his full concentrated attention from one objective to another, usually with desired, tangible results in each. This gift served henceforward in affairs, national and international. He flitted from office to office, in London, Washington and Moscow; helping to render balances unupsettable while determinedly edging them in the direction of reason and sanity. It was in his earlier concern with promoting the flow of knowledge, about developments in atomic science, between his own country and the United States that, despite the American preoccupation with secrecy, he began to win the confidence of Washington: through the revival of his old friendship with Rutherford's Russian protégé, Kapitza, he began, against the tide of Russian suspicion, to win the confidence of Moscow. Needless to say he did not get all he wanted, but what he did get was important to all three countries, because it sprang from a deep feeling for human beings and human society in general, for the community of nations. Having been one of the main instigators in establishing in his own country the peaceful use of atomic energy for generating power, he began to speak out for control of nuclear arsenals, playing a part in bringing about the Test Ban Treaty. His political - and moral - stance is splendidly defined at the conclusion of Oliphant's tribute to him:

In politics he was an old-fashioned liberal, seeking always the middle way of decency and fairness. If he was intolerant in any way, it was of inhumanity, the greed and self-seeking of both the extreme right and the extreme left. He never sought power, but when it came to him, he exercised it with wisdom and restraint.

William Cooper is the pseudonym of the novelist Harry Hoff; his most recent book is Scenes from Later Life (Macmillan, London, 1983). From 1958 to 1972 he was personnel consultant to the United Kingdom Atomic Energy Authority and the Central Electricity Generating Board.

\section{A feeling for the unfathomable}

\section{Martin Gardner}

Reality and Empathy: Physics, Mind and

Science in the 21st Century.

By Alex Comfort.

State University of New York Press:

1984. Pp.272. Hbk \$39.50; pbk \$12.95.

DR Alex Comfort, trained in classics at Cambridge University, is the British gerontologist who made a fortune with his bestsellers The Joy of Sex and More Joy of Sex. Discussions with bright students at the Neuropsychiatric Institute, University of California at Los Angeles, where Comfort now teaches, impelled him to set down on paper the ideas that have swirled in his brain since he discovered the joy of QM (quantum mechanics).

Comfort's main theme, like that of many another recent book, is that QM is such a revolutionary new way of looking at the Universe that if it could be "popularly empathized, it would be a blockbuster" (p.25). By "empathize" Comfort means made so intuitively clear that nonphysicists could feel what it is all about.

The book's first sentence, "Worlds are created by brains", is intentionally ambiguous. You quickly learn that "world" means a world-model, or map, of reality, but later on you encounter the view that perhaps brains have created the outside world as well. Objective reality and mind could be related by what Douglas Hofstadter calls a "strange loop". Somehow - just how is the ultimate mystery - Being was able to bifurcate into matter and minds that allow the matter to see itself. Matter and mind may be epiphenomena of one another, like Escher's picture of two hands, each sketching the other.

Comfort professes to be immune to the epidemic of "pseudo-east nonsense" now infecting the West - what he calls a mix of "Aquarians, acid-heads, and amateur mystics", speaking "yoga-babble" and tossing up "premature Taoists who write popular books on physics"' (pp.37-38). The public would do well to stop listening to "itinerant swamis who preach in mottos out of fortune cookies" (p.33), and turn instead to the original sacred literature of Buddhism and Hinduism where they would find that introspection had indeed produced visions in surprising harmony with the empirical results of modern physics.

What do QM and Eastern thought have in common? Comfort believes it is a way of seeing our pluralistic phenomenal world as an illusion produced by an impenetrable, timeless, unfathomable reality. Comfort seldom calls this reality God, preferring instead the impersonal Brahman of Hinduism. Although QM makes no onto-

logical statements, it is nevertheless saturated with anomalies that Comfort thinks support this Eastern insight.

Consider the notorious EPR (EinsteinPodolsky-Rosen) paradox, invented by Einstein and two associates as a thought experiment, but which recently has received strong support from laboratory experiments. Two photons (in one version) are emitted in opposite directions by an interaction that gives them opposing spins. In QM, neither particle has a definite spin until measured, yet the two are so correlated that if you measure $A$, thereby creating, say, a plus spin, $B$ will acquire a minus spin even though it may be light years away. It is worse than that. If $\boldsymbol{A}$ is measured a second time, it again will acquire plus or minus spin with equal probability. If the spin alters, the companion particle instantly changes to the opposite spin. It is like tossing someone a glove, Comfort writes, then if you turn the companion glove inside out, the other glove will at once invert to preserve the pair's opposite handedness.

Einstein believed that his paradox proved the incompleteness of QM. Comfort agrees. The best way out, he thinks, is to adopt what he calls the "thingless universe" of David Bohm, a QM expert who has long been an admirer of Eastern philosophy. In Bohm's vision, particles are "explicates" of an "implicate order", a substrate that is outside our space and time. Comfort likens the particles to Proceedings

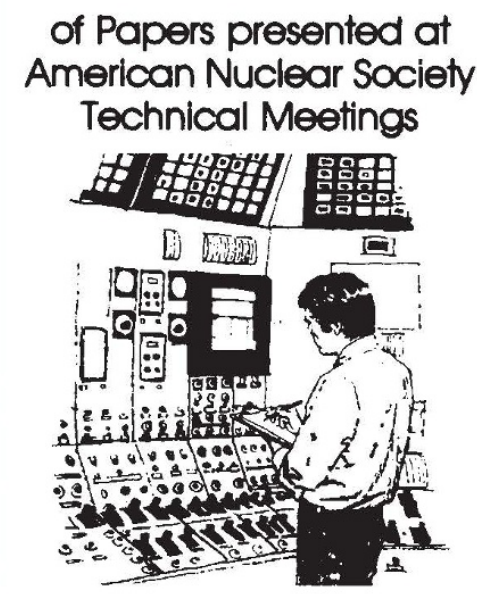

write for free Publications and Services Catalog.

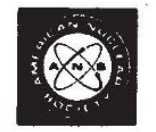

American Nuclear Society 555 N. Kensington Ave. La Grange Park, IL 60525 (312) $352-1661$ 